\title{
USO DE ARDÓSIA NA CONSTRUÇÃO DE CELAS DE MATERNIDADE PARA SUÍNOS: II - AMBIENTE TÉRMICO E AVALIAÇÃO DOS RUÍDOS
}

\section{JAQUELINE DE O. CASTRO ${ }^{1}$, RONY A. FERREIRA ${ }^{2}$, ALESSANDRO T. CAMPOS ${ }^{3}$, TADAYUKI YANAGI JUNIOR ${ }^{4}$, HUGO C. TADEU $^{5}$}

\begin{abstract}
RESUMO: Este trabalho teve o objetivo de avaliar o ambiente térmico e o ruído em celas de maternidade para suínos com divisórias de alvenaria ou com rochas de ardósia. Para as medidas das variáveis de conforto térmico e de ruídos, utilizaram-se de termômetros e decibelímetro. No interior das celas e para a análise estatística, foram usados doze matrizes e cento e trinta e nove leitões, distribuídos em delineamento em blocos casualizados, em esquema de parcelas subdivididas. Os resultados mostraram que, no período da manhã, em ambos os tratamentos, as condições de conforto térmico foram mais adequadas para as matrizes, enquanto no período da tarde, mais adequadas para os leitões; com relação ao ruído, este foi menor nas celas de alvenaria. De forma geral, o ambiente no interior das celas construídas em ardósia apresentou umidade relativa mais baixa, e ITGU e temperatura mais elevada que as celas construídas em alvenaria. O nível de ruídos permaneceu dentro dos limites considerados ideais para suínos em ambos os tratamentos.
\end{abstract}

PALAVRAS-CHAVE: ambiência, ruído, divisórias, maternidade de suínos.

\section{USE OF SLATE TO BUILT SWINE NURSERY CELLS: II - THERMAL ENVIRONMENT AND NOISE EVALUATION}

\begin{abstract}
The aim of the present study was to evaluate the thermal environment and noise levels in swine farrowing cells built with masonry or slate. Thermometers and sound level meter equipment were used to measure the thermal comfort variables. Inside the cells and for the statistical analysis, twelve sows and one hundred thirty-nine piglets were used, distributed in a randomized blocks design in a split-plot arrangement. The results showed that in the morning, in both treatments, the thermal comfort conditions were more suitable for sows, while in the afternoon it was more suitable for piglets. The noise was lower in the masonry cells. Overall, the environment inside in the cells built with slate presented lower relative humidity and, higher BGHI and temperature than those built with masonry. The noise level remained within the thresholds considered as ideal for swine in both treatments.
\end{abstract}

KEYWORDS: environment, noisy, partition walls, farrowing house.

\section{INTRODUÇÃO}

A suinocultura mundial sofreu várias mudanças nas últimas décadas, verificando-se uma diminuição do número de unidades produtivas e um aumento do tamanho dos sistemas produtivos (HECK, 2009). Isso ocorre devido, principalmente, aos avanços na nutrição, genética, manejo e controle ambiental. Acompanhando estas mudanças, vários estudos são realizados com o intuito de se conhecer a interação animal-ambiente-instalação e otimizar o sistema produtivo (SAMPAIO et al., 2007).

\footnotetext{
${ }^{1}$ Doutoranda em Engenharia Agrícola, UFLA, Câmpus Universitário, Caixa Postal 3037, Lavras - MG, Bolsista da CAPES, jaqueline.oliveiracastro@yahoo.com.br.

${ }^{2}$ Prof. Adjunto, Departamento de Engenharia, UFLA, Lavras - MG.

${ }^{3}$ Prof. Adjunto, Departamento de Zootecnia, UFVJM, Diamantina - MG.

${ }^{4}$ Prof. Associado, Departamento de Engenharia, UFLA, Lavras - MG.

${ }^{5}$ Graduando em Agronomia, UFLA, Lavras - MG.

Recebido pelo Conselho Editorial em: 20-9-2011
}

Aprovado pelo Conselho Editorial em: 11-9-2012 
Devido às exigências do mercado internacional, interessado na qualidade do produto final, bem como na eficiência dos processos de produção, trabalhos na área têm sido realizados sobre o tema bem-estar animal (NÄÄS et al., 2008; OLIVEIRA et al., 2008), procurando otimizar os processos de produção.

Diversos trabalhos mostram que técnicas de análise de imagens, estudo de vocalização e de níveis de pressão sonora são métodos não invasivos que podem indicar as respostas do animal em situações adversas (BORGES, 2008; MOURA et al., 2008). De acordo com BORGES et al. (2010), essas técnicas utilizam o próprio animal como "biossensor" frente às adversidades, em um sistema de produção intensiva, consistindo-se em ferramenta auxiliar na tomada de decisões, a fim de se atingirem níveis produtivos cada vem mais satisfatórios, visando a proporcionar aos animais condições ideais de bem-estar.

Por ser uma unidade edificada com a finalidade de abrigar a matriz e os leitões, a maternidade torna-se, no processo produtivo suinícola, o maior desafio, pois dois ambientes distintos devem ser avaliados e com exigências bem diferenciadas (PANDORFI et al., 2004). Segundo NÄ̈̈S (1989), a temperatura de conforto para leitões varia entre $32^{\circ} \mathrm{C}$ e $28{ }^{\circ} \mathrm{C}$, na primeira semana, com decréscimo de $2{ }^{\circ} \mathrm{C}$ para cada semana de vida, até o desmame, e para matrizes está entre $12{ }^{\circ} \mathrm{C}$ e $18{ }^{\circ} \mathrm{C}$ (TEIXEIRA, 1997).

Dessa forma, o uso de outros materiais construtivos pode ser uma forma de melhorar o ambiente nesta instalação. Entretanto, para que um novo material de construção seja implantado, estudos relacionados ao ambiente e bem-estar devem ser conduzidos para que não ocorram perdas produtivas relacionadas a esses materiais.

A ardósia, rocha que sofreu metamorfismo regional sobre rochas sedimentares clásticas finas, apresenta granulação fina e foliação tabular perfeita (COSTA et al., 2001). Atributos como durabilidade e facilidades de manutenção e limpeza são características que asseguram a confiabilidade de seu uso em várias aplicações, na construção civil, podendo ser aparafusada, montada e desmontada com certa facilidade (CHIODI FILHO et al., 2003). Como o material possui elevada impermeabilidade, pode ser lavada e escovada, apresentando, desta forma, melhores condições de higiene e desinfecção se comparada a outros materiais mais porosos, como a alvenaria, por exemplo, mostrando-se interessante sua avaliação para ser empregada nas instalações zootécnicas.

Este trabalho teve como objetivo avaliar o ambiente térmico e o nível de ruídos em celas de maternidade para suínos confeccionadas em ardósia, em comparação com celas confeccionadas com alvenaria de tijolos.

\section{MATERIAL E MÉTODOS}

Este trabalho foi conduzido em uma granja comercial de suínos, de ciclo completo, durante os meses de abril e maio de 2009, contemplando o ciclo completo dos leitões na maternidade (do nascimento ao desmame). A granja localiza-se na Mesorregião Metropolitana de Belo Horizonte-MG, latitude $19^{\circ} 26^{\prime} 56^{\prime \prime} \mathrm{S}$, longitude $44^{\circ} 44^{\prime} 52^{\prime \prime} \mathrm{O}$ e altitude de $718 \mathrm{~m}$, cujo clima, de acordo com Köeppen, classifica-se como Aw (tropical chuvoso com temperatura média de $20,9{ }^{\circ} \mathrm{C}$, temperatura máxima de $28,2{ }^{\circ} \mathrm{C}$, temperatura mínima de $15,9{ }^{\circ} \mathrm{C}$, umidade relativa média de $70,5 \%$ e precipitação anual de $1.328,7 \mathrm{~mm})$.

$\mathrm{O}$ experimento foi conduzido em salas de maternidade com as seguintes características construtivas: largura de $8 \mathrm{~m}$ e comprimento de $21 \mathrm{~m}$, telhado em duas águas coberto com telhas tipo francesas, pé-direito de 3,6 m, dotadas de cortinas de polietileno amarelo nas laterais da instalação. Cada sala possuía 24 celas de maternidade, com $3 \mathrm{~m}$ de comprimento por $1,70 \mathrm{~m}$ de largura e altura de $0,5 \mathrm{~m}$, como mostra a Figura 1 . O escamoteador possuía $1,70 \mathrm{~m}$ de comprimento por $0,5 \mathrm{~m}$ de largura, dotado de uma lâmpada incandescente de $150 \mathrm{~W}$, para aquecimento dos leitões, instalada na parte superior, abaixo da tampa móvel. 
(a)

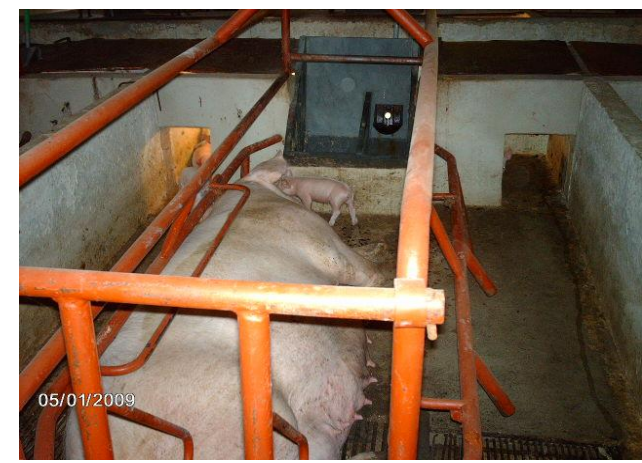

(b)

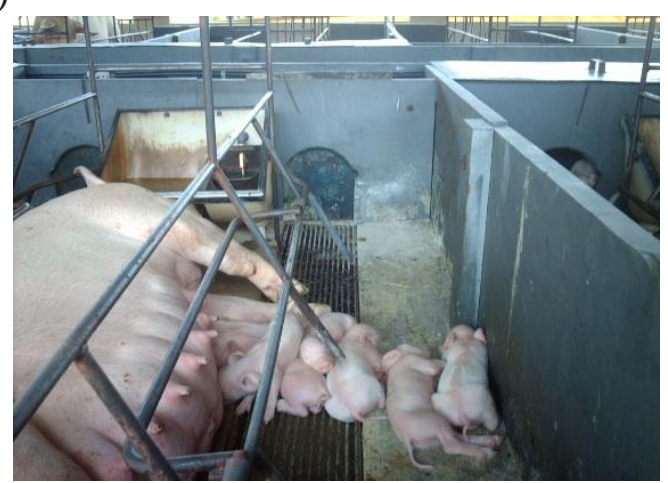

FIGURA 1. Celas de maternidade confeccionadas em alvenaria (a) e ardósia(b). Nursery stalls built in slate (a) and masonry (b).

As medidas ocorreram em duas salas diferentes, onde foram alojados 12 matrizes e 139 leitões de linhagem comercial, sendo avaliadas seis celas de maternidade por tratamento, com unidade experimental composta por uma cela onde se alojavam a matriz e sua leitegada. Os tratamentos foram definidos pelos tipos de materiais utilizados para a construção das celas de maternidade, ou seja, o primeiro tratamento de alvenaria de tijolos furados, e o segundo tratamento, de placas de ardósia, com espessuras de $17 \mathrm{~cm}$ e $5 \mathrm{~cm}$, respectivamente (Figura 1).

O manejo de rotina na maternidade consistia na alimentação das matrizes, às $7 \mathrm{~h} 30,13 \mathrm{~h} 30$ e às $17 \mathrm{~h}$, sendo que, nos dois primeiros dias de vida dos leitões, era realizado o manejo tradicional de corte dos dentes e da cauda, e ministradas medicações preventivas (aplicação de glicose e ferro); posteriormente, eram feitas outras medicações preventivas.

O ambiente térmico no interior das instalações foi monitorado a partir do nascimento dos leitões, extendendo-se a todo o período experimental, sendo que, a cada três dias, era feito intervalo de um dia. Os instrumentos foram instalados à meia altura dos animais, ou seja, aproximadamente $40 \mathrm{~cm}$ do piso, e os dados, coletados a cada hora (60 minutos), com início às $7 \mathrm{~h} 30$ e término às 15h30. Foram medidas as temperaturas de bulbo seco $\left(t_{\mathrm{bs}}\right)$ e de globo negro $\left(\mathrm{t}_{\mathrm{gn}}\right)$, a umidade relativa do ar (UR) e a velocidade do ar $\left(\mathrm{V}_{\mathrm{ar}}\right)$ no interior das celas de maternidade, por meio dos seguintes instrumentos: termoigrômetro digital (Alla France modelo 910.15 / f, precisão de $1{ }^{\circ} \mathrm{C}$ e $8 \%$ para t e UR, respectivamente), utilizado para a determinação da $t_{b s}$ e $t_{g n}$, e anemômetro digital (Instrutherm TR-176, $\pm 2 \mathrm{~m} \mathrm{~s}^{-1}$ ). A avaliação do ambiente térmico foi realizada pelo índice de temperatura de globo e umidade (ITGU), e pela carga térmica radiante.

A carga térmica radiante, descrita por ESMAY (1982), foi calculada pela equação 1.

$$
\mathrm{CTR}=\sigma\left(100\left\{\left[2,51\left(\mathrm{~V}_{\mathrm{ar}}\right)^{0,5}\left(\mathrm{~T}_{\mathrm{gn}}-\mathrm{T}_{\mathrm{bs}}\right)+(\mathrm{Tg} / 100)^{4}\right]^{0,25}\right\}\right)^{4}
$$

em que,

CTR - carga térmica radiante, $\mathrm{W} \mathrm{m}^{-2}$

$\mathrm{V}_{\mathrm{ar}}$ - velocidade do vento, $\mathrm{m} \mathrm{s}^{-1}$;

$\mathrm{T}_{\mathrm{gn}}$ - temperatura de globo negro, $\mathrm{K}$;

$\mathrm{T}_{\mathrm{bs}}$ - temperatura de bulbo seco, $\mathrm{K}$, e

$\sigma-5,67 \times 10^{-8}$ (Constante de Stefan-Boltzmann), $\mathrm{K}^{-4} \mathrm{~W} \mathrm{~m}^{-2}$.

O índice de temperatura do globo e de umidade (ITGU), descrito por BUFFINGTON et al. (1981), foi calculado pela eq.(2):

$$
\mathrm{ITGU}=\mathrm{T}_{\mathrm{gn}}+0,36 \mathrm{~T}_{\mathrm{po}}-330,08
$$

em que,

$\mathrm{T}_{\mathrm{gn}}$ - temperatura de globo negro, $\mathrm{K}$;

$\mathrm{T}_{\mathrm{po}}$ - temperatura de ponto de orvalho, $\mathrm{K}$. 
A temperatura das superfícies $\left(\mathrm{t}_{\mathrm{s}}\right)$ dos materiais utilizados na confecção das celas de maternidade (alvenaria e ardósia) foi medida nos mesmos horários de coleta dos dados ambientais (início às $7 \mathrm{~h} 30$ e término às $15 \mathrm{~h} 30$, com intervalo de 60 minutos), por meio de um pirômetro (IMPAC IP-550, $\pm 2{ }^{\circ} \mathrm{C}$ ), durante todo o período experimental, bem como a temperatura superfícial (nuca) das matrizes e dos leitões foi medida por duas vezes ao dia, às $9 \mathrm{~h}$ e às $15 \mathrm{~h}$, por meio de um pirômetro.

O nível de ruídos, em decibéis $(\mathrm{dB})$, emitidos pelos animais, foi medido em todo o período experimental, a partir do nascimento dos leitões e com a mesma periodicidade das avaliações ambientais, junto às mesmas celas onde foram coletados os dados ambientais, com o sensor posicionado a $1,5 \mathrm{~m}$ de altura do piso. O intervalo de coleta de dados foi de 60 minutos, com início às $8 \mathrm{~h}$ e término às $16 \mathrm{~h}$, utilizando um decibelímetro (Instrutherm TDL 400, $\pm 3,5 \mathrm{~dB}$ ).

As variáveis ambientais ( $\mathrm{t}_{\mathrm{bs}}$, UR, ITGU, CTR, $\mathrm{t}_{\mathrm{s}}$, ruído) e a temperatura da superfície corporal de matrizes e leitões foram definidas, utilizando delineamento em blocos casualizados, em esquema de parcelas subdivididas, sendo as parcelas os tratamentos (alvenaria e ardósia), e as subparcelas, os horários, obedecendo ao seguinte modelo matemático:

$$
\mathrm{Y}_{\mathrm{ijk}}=\mu+\mathrm{B}_{\mathrm{j}}+\mathrm{M}_{\mathrm{i}}+\varepsilon_{\mathrm{ij}}+\mathrm{H}_{\mathrm{k}}+\theta_{\mathrm{jk}}+\mathrm{MH}_{\mathrm{ik}}+\delta_{\mathrm{ijk}}
$$

em que,

$\mathrm{Y}_{\mathrm{ijk}}$ - efeito do material de construção i (i=1 e 2) no horário j (j=07h30min...16h), na repetição $\mathrm{k}(\mathrm{k}=1,2 \ldots 6)$;

$\mu$ - média geral;

$\mathrm{B}_{\mathrm{j}}$ - efeito do posicionamento da cela $\mathrm{j}$;

$\mathrm{M}_{\mathrm{i}}$ - efeito do material de construção i;

cij - erro aleatório a;

$\mathrm{H}_{\mathrm{k}}$ - efeito do horário $\mathrm{k} ; \theta \mathrm{jk}$ - erro aleatório b;

$\mathrm{MH}_{\mathrm{ik}}$ - efeito da interação do material de construção i com o horário de coleta de dados k; $\delta_{\mathrm{ijk}}$ - erro aleatório c.

\section{RESULTADOS E DISCUSSÃO}

Os resultados da caracterização ambiental obtidos podem ser visualizados na Tabela 1. Nota-se que o material de construção influenciou $(\mathrm{P}<0,05)$ alguns elementos climáticos do ambiente, sendo que a temperatura de bulbo seco ( $\mathrm{t}_{\mathrm{bs}}$ ) e o índice de temperatura de globo e umidade (ITGU), no interior das instalações, foram superiores nas celas construídas de ardósia, enquanto a umidade relativa (UR) foi inferior $(\mathrm{P}<0,05)$.

TABELA 1. Valores de temperatura de bulbo seco $\left({ }^{\circ} \mathrm{C}\right)$, umidade relativa do ar $(\%)$ e índice de temperatura de globo e umidade (ITGU), em maternidade de suínos com celas de alvenaria ou de ardósia. Values of dry bulb temperature $\left({ }^{\circ} \mathrm{C}\right)$, relative humidity of the air (\%), black globe temperature and humidity index (BGTHI) in the swine nursery stalls, built of slate and masonry.

\begin{tabular}{ccc|cc|cc}
\hline & \multicolumn{2}{c|}{$\mathrm{t}_{\mathrm{bs}}$} & \multicolumn{2}{c|}{ UR } & \multicolumn{2}{c}{ ITGU } \\
\hline Horários & Alvenaria & Ardósia & Alvenaria & Ardósia & Alvenaria & Ardósia \\
\hline $7 \mathrm{~h} 30$ & $19,17 \mathrm{a}$ & $19,50 \mathrm{a}$ & $86,33 \mathrm{a}$ & $88,17 \mathrm{~b}$ & $66,33 \mathrm{a}$ & $67,17 \mathrm{~b}$ \\
$8 \mathrm{~h} 30$ & $20,17 \mathrm{a}$ & $20,33 \mathrm{a}$ & $87,50 \mathrm{a}$ & $88,50 \mathrm{a}$ & $67,83 \mathrm{a}$ & $68,33 \mathrm{a}$ \\
$9 \mathrm{~h} 30$ & $21,17 \mathrm{a}$ & $22,00 \mathrm{~b}$ & $87,17 \mathrm{a}$ & $86,83 \mathrm{a}$ & $69,17 \mathrm{a}$ & $70,17 \mathrm{~b}$ \\
$10 \mathrm{~h} 30$ & $22,83 \mathrm{a}$ & $23,50 \mathrm{~b}$ & $81,17 \mathrm{a}$ & $78,17 \mathrm{~b}$ & $71,00 \mathrm{a}$ & $71,83 \mathrm{~b}$ \\
$12 \mathrm{~h} 30$ & $25,00 \mathrm{a}$ & $26,00 \mathrm{~b}$ & $70,83 \mathrm{a}$ & $66,17 \mathrm{~b}$ & $73,33 \mathrm{a}$ & $74,33 \mathrm{~b}$ \\
$13 \mathrm{~h} 30$ & $26,00 \mathrm{a}$ & $27,00 \mathrm{~b}$ & $65,33 \mathrm{a}$ & $60,33 \mathrm{~b}$ & $73,83 \mathrm{a}$ & $75,17 \mathrm{~b}$ \\
$14 \mathrm{~h} 30$ & $26,17 \mathrm{a}$ & $27,83 \mathrm{~b}$ & $62,17 \mathrm{a}$ & $57,83 \mathrm{~b}$ & $74,33 \mathrm{a}$ & $75,50 \mathrm{~b}$ \\
$15 \mathrm{~h} 30$ & $26,33 \mathrm{a}$ & $28,00 \mathrm{~b}$ & $60,50 \mathrm{a}$ & $55,83 \mathrm{~b}$ & $74,00 \mathrm{a}$ & $75,33 \mathrm{~b}$ \\
\hline C.V. $(\%)$ & \multicolumn{3}{|c|}{1,91} & \multicolumn{3}{|c|}{1,42} \\
\hline
\end{tabular}

Médias seguidas de mesma letra na linha são estatisticamente iguais, pelo teste de $\mathrm{F}(\mathrm{P}<0,05)$. 
Com exceção dos horários entre $7 \mathrm{~h} 30$ e $8 \mathrm{~h} 30$, a t de alvenaria ao longo do dia (Figura 2), sendo a maior amplitude térmica encontrada nas celas de ardósia. $\mathrm{O}$ maior valor de $\mathrm{t}_{\mathrm{bs}}$ foi observado às $15 \mathrm{~h} 30 \mathrm{~min}$ nas celas de ardósia, e a maior diferença entre os tratamentos ocorreu neste mesmo horário.

Analisando o ambiente para os leitões, pode-se observar que apenas nas celas de ardósia, no horário de $15 \mathrm{~h} 30$, o valor de $\mathrm{t}_{\mathrm{bs}}$ mostrou-se adequado ao conforto térmico para a categoria, na terceira semana de vida (Figura 2a). Nota-se ainda que, em ambos os tratamentos, principalmente para a primeira e segunda semanas de vida dos leitões, as médias da $t_{\mathrm{bs}}$ na região em torno da matriz estiveram abaixo do conforto térmico para esses animais, o que pode ocasionar maior procura pela fonte de calor.

(a)

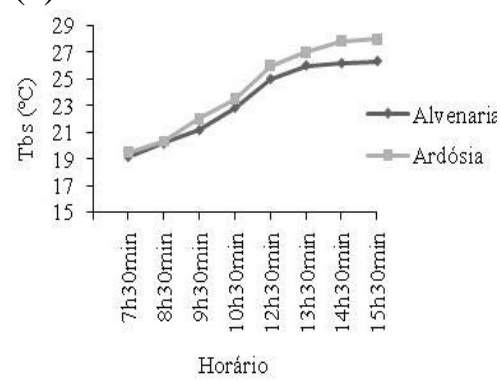

(b)

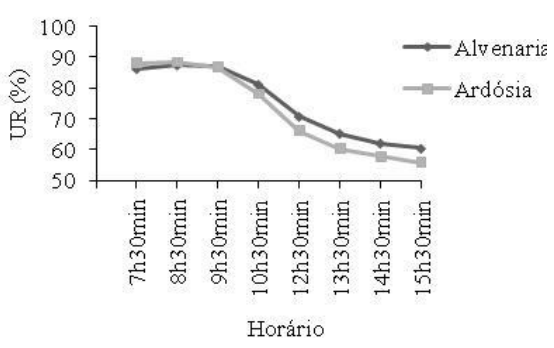

(c)

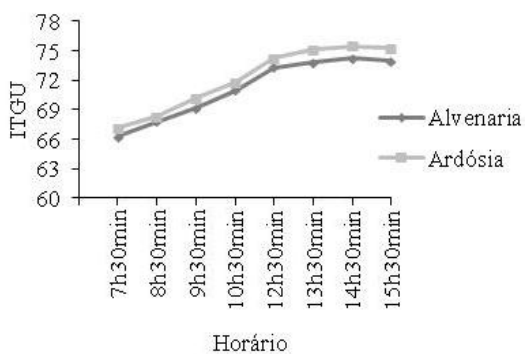

FIGURA 2. Valores de temperatura de bulbo seco $\left({ }^{\circ} \mathrm{C}\right)$ (a), umidade relativa do ar (\%) (b) e índice de temperatura de globo e umidade (ITGU) (c), em maternidade de suínos com celas de maternidade de alvenaria ou de ardósia. Values of dry bulb temperature $\left({ }^{\circ} \mathbf{C}\right)$, relative humidity of the air (\%), black globe temperature and humidity index (BGTHI) in the swine nursery stalls, built of slate and masonry.

Comparando-se os valores médios de $\mathrm{t}_{\mathrm{bs}}$ à zona de conforto térmico para matrizes, observou-se que nenhum dos tratamentos proporcionou conforto a essa categoria animal, sendo que o horário de 7 h30 foi o que mais se aproximou do conforto, em ambos os tratamentos (Figura 2a), conforme descreve TEIXEIRA (1997).

Nas celas de ardósia, a $\mathrm{t}_{\mathrm{bs}}$ foi, em média, $0,91{ }^{\circ} \mathrm{C}$ superior à $\mathrm{t}_{\mathrm{bs}}$ observada nas celas de alvenaria. Nos dois tratamentos, o ambiente térmico para as porcas mostrou-se fora da zona de conforto descrita por TEIXEIRA (1997), caracterizando-se como estresse de calor para os animais. Os maiores valores de $t_{b s}$ e ITGU observados com o uso de ardósia podem ter ocorrido em função da maior capacidade de reflexão da energia radiante pelo material e menor absorção desta energia, em relação às celas de alvenaria. Do mesmo modo, a transferência de calor pela ardósia é maior que na cela de alvenaria em função da constituição do material, uma vez que a ardósia apresenta, em sua composição, partículas mais próximas, facilitando a transferência de calor.

Os valores de UR nas celas construídas em ardósia foram menores, exceto para os horários das $8 \mathrm{~h} 30$ e $7 \mathrm{~h} 30$. A partir de $10 \mathrm{~h} 30$ foi observada diminuição da UR, que pode ser atribuída ao manejo de abertura das cortinas laterais, o que permitiu que a ventilação influenciasse na dissipação do vapor d'água no interior da instalação.

Observou-se que, para os dois materiais de construção avaliados, as médias da UR foram superiores à faixa de conforto para suínos, citada por NÄÄS (1989), entre 60 e 70\%. No período entre $7 \mathrm{~h} 30 \mathrm{~min}$ e $10 \mathrm{~h} 30$, a $\mathrm{t}_{\mathrm{bs}}$ elevada, aliada a altos valores de vapor d'água no ambiente, pode diminuir a habilidade das matrizes em dissipar calor, pois o ar saturado compromete a perda de calor latente pelo sistema respiratório, proporcionando um ambiente mais estressante ao animal. No período da tarde, a UR no microambiente da cela em alvenaria permaneceu dentro dos limites de conforto. Entretanto, para o tratamento com ardósia, apenas nos horários das $12 \mathrm{~h} 30$ e $13 \mathrm{~h} 30$ observou-se condição de conforto às matrizes, sendo encontrados nos horários de $7 \mathrm{~h} 30$ às $10 \mathrm{~h} 30$ 
valores superiores aos recomendados, e nos horários de $14 \mathrm{~h} 30$ e $15 \mathrm{~h} 30$, valores inferiores aos recomendados para esses animais.

Com relação aos valores de ITGU, estes se apresentaram menores no início do dia. Apenas para o horário de 8h30min não se observou diferença entre os tratamentos $(\mathrm{P}>0,05)$. Os maiores valores de ITGU, em todos os horários, ocorreram nas celas de ardósia. Ao se compararem os valores de ITGU obtidos com os considerados como de conforto para leitões, entre 82 e 84 (PANDORFI et al., 2005), tanto as celas de alvenaria quanto as de ardósia não atenderam aos valores de conforto. No entanto, os valores obtidos no interior das celas de ardósia mostraram que se aproximam mais daqueles considerados como de conforto para leitões.

Para as matrizes, em ambos os tratamentos, o ITGU no período da manhã pode ser considerado confortável; entretanto, no período da tarde, os valores deste índice distanciaram-se do ideal, que é de 72, conforme descreve TURCO et al. (1998). Isso pode levar ao aumento na frequência respiratória, além de aumentar a temperatura retal.

Na Tabela 2, apresentam-se os resultados médios diários da carga térmica radiante (CTR), temperatura da superfície dos materiais (TS) e do nível de ruídos, observados nos microambientes estudados nos horários de $7 \mathrm{~h} 30$ às $16 \mathrm{~h}$.

TABELA 2. Valores de carga térmica radiante $\left(\mathrm{W} \mathrm{m}^{-2}\right)$, temperatura da superfície dos materiais avaliados $\left({ }^{\circ} \mathrm{C}\right)$ e nível de ruídos $(\mathrm{dB})$, em maternidade de suínos com celas de maternidade de alvenaria ou de ardósia. Values of thermal heat load (CTR), surface temperature of the materials $\left(t_{s}\right)$ in the swine nursery stalls, built of slate and masonry.

\begin{tabular}{ccc|cc|cc}
\hline \multicolumn{3}{c|}{ CTR } & \multicolumn{2}{c|}{$\mathrm{t}_{\mathrm{s}}$} & \multicolumn{2}{c}{ Ruído } \\
\hline Horários & Alvenaria & Ardósia & Alvenaria & Ardósia & Alvenaria & Ardósia \\
\hline $7 \mathrm{~h} 30-8 \mathrm{~h}$ & $419,33 \mathrm{a}$ & $419,83 \mathrm{a}$ & $21,50 \mathrm{a}$ & $21,33 \mathrm{a}$ & $69,50 \mathrm{a}$ & $73,00 \mathrm{~b}$ \\
$8 \mathrm{~h} 30-9 \mathrm{~h}$ & $425,50 \mathrm{a}$ & $435,17 \mathrm{a}$ & $21,67 \mathrm{a}$ & $21,50 \mathrm{a}$ & $67,00 \mathrm{a}$ & $71,50 \mathrm{~b}$ \\
$9 \mathrm{~h} 30-10 \mathrm{~h}$ & $435,67 \mathrm{a}$ & $447,00 \mathrm{a}$ & $22,67 \mathrm{a}$ & $23,17 \mathrm{a}$ & $61,17 \mathrm{a}$ & $69,50 \mathrm{~b}$ \\
$10 \mathrm{~h} 30-11 \mathrm{~h}$ & $452,00 \mathrm{a}$ & $456,00 \mathrm{a}$ & $24,67 \mathrm{a}$ & $24,83 \mathrm{a}$ & $60,33 \mathrm{a}$ & $61,67 \mathrm{a}$ \\
$12 \mathrm{~h} 30-13 \mathrm{~h}$ & $466,00 \mathrm{a}$ & $481,50 \mathrm{a}$ & $27,00 \mathrm{a}$ & $27,17 \mathrm{a}$ & $63,00 \mathrm{a}$ & $65,17 \mathrm{a}$ \\
$13 \mathrm{~h} 30-14 \mathrm{~h}$ & $468,17 \mathrm{a}$ & $480,83 \mathrm{a}$ & $27,67 \mathrm{a}$ & $27,83 \mathrm{a}$ & $65,33 \mathrm{a}$ & $70,00 \mathrm{~b}$ \\
$14 \mathrm{~h} 30-15 \mathrm{~h}$ & $478,00 \mathrm{a}$ & $478,17 \mathrm{a}$ & $27,83 \mathrm{a}$ & $28,17 \mathrm{a}$ & $58,83 \mathrm{a}$ & $60,17 \mathrm{a}$ \\
$15 \mathrm{~h} 30-16 \mathrm{~h}$ & $469,83 \mathrm{a}$ & $476,00 \mathrm{a}$ & $27,50 \mathrm{a}$ & $27,83 \mathrm{a}$ & $61,50 \mathrm{a}$ & $64,33 \mathrm{~b}$ \\
\hline C.V. $(\%)$ & \multicolumn{2}{c|c}{19,29} & \multicolumn{3}{|c|}{2,28} & \multicolumn{2}{c}{3,19} \\
\hline
\end{tabular}

Médias seguidas de mesma letra na linha são estatisticamente iguais, pelo teste de $\mathrm{F}(\mathrm{P}<0,05)$

Pelos resultados apresentados na Tabela 2, nota-se que a carga térmica radiante (CTR) e a temperatura da superfície $\left(\mathrm{t}_{\mathrm{s}}\right)$ dos materiais não variaram $(\mathrm{P}>0,05)$ no interior das celas construídas com os diferentes materiais, para cada horário avaliado.

Na Figura 3, apresenta-se o comportamento dos valores médios encontrados para a carga térmica radiante (a), temperatura da superfície dos materiais (b) e nível de ruídos (c).

As médias horárias encontradas para a CTR (Figura 3c) seguiram o mesmo padrão encontrado por CAMERINE et al. (2009), que observaram aumento nos valores da CTR ao longo da manhã, com declínio após as $14 \mathrm{~h}$. Quando as médias foram comparadas aos valores de conforto de $450 \mathrm{~W} \mathrm{~m}^{-2}$, conforme descrevem BAÊTA \& SOUZA (2010), apenas o horário de 10h30 apresentou-se próximo ao ideal, sendo que, no período da tarde, as matrizes podem sofrer maior desconforto ambiental. 
(a)

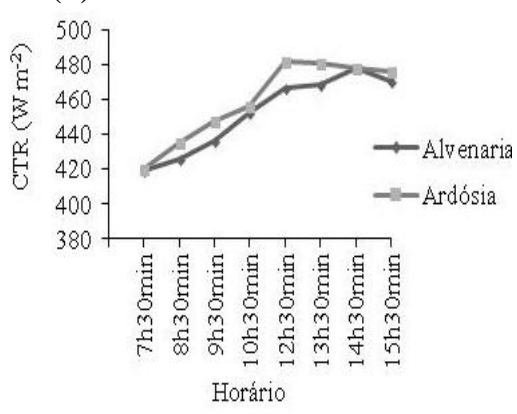

(b)

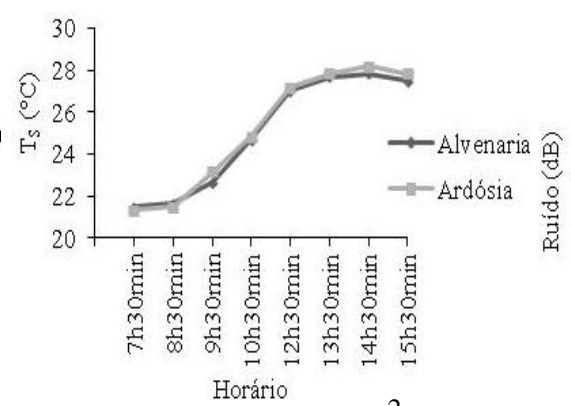

(c)

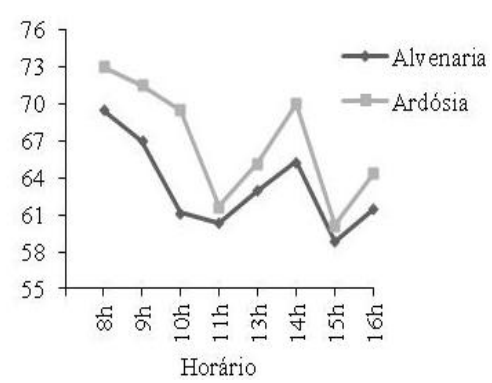

FIGURA 3. Valores de carga térmica radiante $\left(\mathrm{W} \mathrm{m}^{-2}\right)$ (a), temperatura da superfície dos materiais avaliados $\left({ }^{\circ} \mathrm{C}\right)$ (b) e nível de ruídos $(\mathrm{dB})(\mathrm{c})$, em maternidade de suínos com celas de maternidade de alvenaria ou de ardósia. Values of thermal heat load (CTR), surface temperature of the materials $\left(t_{s}\right)$ in the swine nursery stalls, built of slate and masonry.

Não se observou diferença significativa $(\mathrm{P}>0,05)$ entre as temperaturas de superfícies dos materiais avaliados (Tabela 2), pois eles apresentaram comportamentos semelhantes (Figura 3b). Os valores ficaram, em média, muito próximos, não ultrapassando $1{ }^{\circ} \mathrm{C}$ de diferença.

O nível de ruídos no interior das instalações foi superior $(\mathrm{P}<0,05)$ nas celas construídas com ardósia (Tabela 2). Observou-se ainda que o nível de ruídos oscilou durante o dia (Figura 3c), sendo os menores valores encontrados nos horários de menor intensidade de manejo, estes resultados entram em concordância com aqueles obtidos por SAMPAIO et al. (2007).

A intensidade de ruído no interior da sala com celas em ardósia foi superior $(\mathrm{P}<0,05)$ aos encontrados na sala com celas em alvenaria ao longo do dia, exceto nos horários de $11 \mathrm{~h}, 13 \mathrm{~h}$ e $15 \mathrm{~h}$ (Tabela 2). Porém, os valores médios encontrados em ambos os tratamentos mostram-se inferiores ao valor máximo recomendado para a suinocultura, que é de até $85 \mathrm{~dB}$ (MOURA \& SARUBBI, 2009). O nível de ruídos estando abaixo deste valor não oferece risco ao bem-estar dos suínos (TOLON et al., 2010).

Ao avaliar a sazonalidade da ambiência acústica em creche de suínos, BARACHO et al. (2008) observaram que os níveis de ruído na instalação não foram influenciados pela estação do ano, entretanto observaram oscilações desses níveis durante o dia, o que está de acordo com os resultados encontrados no presente trabalho.

$\mathrm{O}$ manejo de arraçoamento das matrizes e a castração dos leitões foram as atividades que provocaram maior elevação nos níveis de ruídos (acima de $90 \mathrm{~dB}$ ). De acordo com SILVA (2008), as situações de manejo de leitões que mais provocam estresse, com as maiores médias de intensidade sonora, são corte de cauda, corte de dente, castração e suplementação intramuscular de ferro.

A temperatura da superfície corporal de matrizes e leitões é apresentada na Tabela 3.

TABELA 3. Temperatura média da superfície corporal $\left({ }^{\circ} \mathrm{C}\right)$ das matrizes e leitões mantidos em maternidade de suínos com celas de maternidade de alvenaria e ardósia. Average body surface temperature $\left({ }^{\circ} \mathrm{C}\right)$ of sows and piglets in the swine nursery stalls, built of slate and masonry.

\begin{tabular}{cccccc}
\hline \multirow{2}{*}{ Categoria Animal } & \multicolumn{3}{c}{$9 \mathrm{~h}$} & \multicolumn{3}{c}{$15 \mathrm{~h}$} & \multirow{2}{*}{ C.V. $(\%)$} \\
\cline { 2 - 5 } & Alvenaria & Ardósia & Alvenaria & Ardósia & \\
\hline Leitões & $31,83 \mathrm{a}$ & $32,50 \mathrm{~b}$ & $33,67 \mathrm{a}$ & $34,67 \mathrm{~b}$ & 1,29 \\
Matrizes & $30,67 \mathrm{a}$ & $31,17 \mathrm{a}$ & $33,16 \mathrm{a}$ & $34,00 \mathrm{a}$ & 2,23 \\
\hline
\end{tabular}

Médias seguidas de mesma letra na linha são estatisticamente iguais, pelo teste de $\mathrm{F}(\mathrm{P}<0,05)$ 
Os leitões alojados nas celas de ardósia apresentaram maiores $(\mathrm{P}<0,05)$ valores de temperatura superficial nos horários avaliados, o que pode ser atribuído ao fato de a ardósia proporcionar um microambiente, dentro das instalações, mais quente que a alvenaria. Entretanto, para as matrizes, o diferente ambiente proporcionado pelos tratamentos não foi capaz de promover alterações em sua temperatura de superfície $(\mathrm{P}>0,05)$.

\section{CONCLUSÕES}

Os materiais de construção modificaram o ambiente térmico no interior das instalações. A instalação de celas de maternidade construída com ardósia, de forma geral, apresentou-se mais quente $\left(0,91^{\circ} \mathrm{C}\right)$ e menos úmida $(2,40 \%)$ que a instalação com celas de maternidade construída em alvenaria.

O ITGU apresentou diferenças entre os tratamentos, sendo que, nas celas construídas em ardósia, foram encontrados os maiores valores para este índice (75,13 e 72,73; alvenaria e ardósia, repectivamente).

A modificação ambiental causada pelos materias de construção afetou o nível de ruídos em seu interior, com intensidade maior para celas de ardósia. Entretanto, o nível de ruídos em ambas as instalações $(63,33 \mathrm{~dB}$ e $66,92 \mathrm{~dB}$; alvenaria e ardósia, repectivamente) permaneceu dentro dos limites considerados ideais para suínos, de $85 \mathrm{~dB}$.

A temperatura superficial dos materiais de construção das baias apresentou comportamento semelhante entre os tratamentos ao longo do dia.

Para que um novo material de construção seja adotado, além de estudos relacionados ao ambiente e ao bem-estar dos animais, deve-se levar, também em consideração, suas características sanitárias, a economicidade que o material representa e disponibilidade local do produto.

\section{REFERÊNCIAS}

BAÊTA, F. C.; SOUZA, C. F. Ambiência em edificações rurais conforto animal. 2. ed. Viçosa: Editora UFV, 2010. 269 p.

BARRACHO, M. S.; TOLON, Y. B.; NÄÄS, I. A.; ROJAS, M. Sazonalidade da ambiência térmica, aérea e acústica em creche e terminação de suínos. Revista Brasileira de Engenharia de Biossistemas, Campinas, v.2, n.3, p.201-212, set./dez. 2008.

BORGES, G. Utilização da pressão sonora (ruído) como indicativo de bem-estar animal na produção industrial de suínos. 2008. 139 f. Dissertação (Mestrado em Física do Ambiente Agrícola) - Escola Superior de Agricultura "Luiz de Queiroz", Universidade de São Paulo, Piracicaba, 2008.

BORGES, G.; MIRANDA, K. O. S.; RODRIGES, V. C.; RISI, N. Uso da geoestatística para avaliar a captação automática dos níveis de pressão sonora em instalações de creche para suínos. Engenharia Agrícola, Jaboticabal, v.30, n,3, p.377-385, maio/jun. 2010.

BUFFINGTON, D. E.; COLLAZO AROCHO, A.; CANTON, G. H. PITT, D. Black globe humidity index (BGHI) as a comfort equation for dairy cows. Transactions of the ASAE, v.24, n.3, p.711-714, 1981.

CAMERINI, N. L.; NASCIMENTO, J. W. B.; FOOK, M. V. L.; SOARES, E. A.; SILVA, F. A. S. Análise de variáveis ambientais em modelos reduzidos de instalações agropecuárias com forro de resíduo de EVA. Revista Eletrônica de Materiais e Processos, Campina grande, v.4, n.2, p.40-47, 2009.

CHIODI FILHO, C.; RODRIGUES, E. P.; ARTUR, A. C. Ardósias de Minas Gerais, Brasil: características geológicas, petrográficas e químicas. Geociências, São Paulo, v.22, n.2, p.119-127, jul./dez. 2003. 
COSTA, A. G.; CAMPELLO, M. S.; PIMENTA, V. B. Rochas ornamentais e de revestimento de Minas Gerais: Principais ocorrências, caracterização e aplicações na indústria da construção civil. Geonomos, Belo Horizonte, v.7, n.1, p.9-13, jul./dez. 2001.

ESMAY, M. L. Principles of animal environment. West Port CT: ABI, 1982, 325 p.

HECK, A. Fatores que influenciam o desenvolvimento dos leitões na recria e terminação. Acta Scientiae Veterinariae, Porto Alegre, v.37, v.1, p.211-218, out./dez. 2009.

MOURA, D. J.; SARUBI, J. Interação entre ambiência e produtividade na suinocultura industrial: realidade brasileira e as exigências internacionais. Suinocultura Industrial, Campinas, p.28-33, jul. 2009.

MOURA, D. J.; SILVA, W. T.; NÄÄS, I. A.; TOLÓN, Y. A.; LIMA, K. A. O.; VALE, M. M. Real time computer stress monitoring of piglets using vocalization analysis. Computers and Electronics in Agriculture, Amsterdam, v.64, n.1, p.11-18, nov. 2008.

NÄÄS, I. A. Princípios do conforto térmico na produção animal. São Paulo: Editora Ícone, 1989. $183 \mathrm{p}$.

NÄÄS, I. A.; CAMPOS, S. L. S.; BARRACHO, M. S.; TOLON, YAMILA, B. TOLON. Uso de redes neurais artificiais na identificação de vocalização de suínos. Engenharia Agrícola, Jaboticabal, v.8, n.2, p. 204-216, abr./jun. 2008.

OLIVEIRA, C. B.; BORTOLI, E. C.; BARCELLOS, J. O. J. Diferenciação por qualidade da carne bovina: a ótica do bem-estar animal. Ciência Rural, Santa Maria, v.38, n.7, p. 2.092-2.096, out. 2008.

PANDORFI, H.; SILVA, I. J. O.; MOURA, D. J.; SEVEGNAN, K. B. Microclima de abrigos escamoteadores para leitões submetidos a diferentes sistemas de aquecimento no período de inverno. Revista Brasileira de Engenharia Agrícola e Ambiental, Campina Grande, v.9, n.1, p.99106, jan./mar. 2005.

PANDORFI, H.; SILVA, I. J. O.; MOURA, D. J.; MOURA, D. J.; SEVEGNAN, K. B. N. Análise de imagem aplicada ao estudo do comportamento de leitões em abrigo escamoteador. Engenharia Agrícola, Jaboticabal, v.24, n.2, p.274-284, maio/ago. 2004.

SAMPAIO, C. A. P.; NÄÄS, I. A.; SALGADO, D. D.; QUEIRÓS, M. P. G. Avaliação do nível de ruído em instalações para suínos. Revista Brasileira de Engenharia Agrícola e Ambiental, Campina Grande, v.11, n.4, p.436-440, jul./ago. 2007.

SILVA, I. J. O.; PANDORFI, H.; PIEDADE, S. M. S. Influência do sistema de alojamento no comportamento e bem-estar de matrizes suínas em gestação. Revista Brasileira de Zootecnia, Viçosa, v.37, n.7, p.1.319-1.329, jul. 2008.

SILVA, W. T. Desenvolvimento de um sistema de estimativa de bem-estar a partir de dados de vocalização de suínos. 2008. 91f. Dissertação (Mestrado em Engenharia Agrícola) - Faculdade de Engenharia Agrícola, Universidade Estadual de Campinas, Campinas, 2008.

TEIXEIRA, V. H. Construções e ambiência. Lavras: FAEPE, 1997. 181 p.

TOLON, Y. B.; BARRACHO, M. S.; NÄÄS, I. A.; ROJAS, M.; MOURA, D. J. Ambiências térmica, aérea e acústica para reprodutores suínos. Engenharia Agrícola, Jaboticabal, v.30, n.1, p. 113, jan./fev. 2010.

TURCO, S. H. N.; FERREIRA, A. S.; OLIVEIRA, R. F. M.; AGUIAR, M. A.; CECON, P. R.; ARAÚJO, G. G. L. Desempenho de porcas e leitões em maternidade com diferentes sistemas de acondicionamento térmico no inverno. Revista Brasileira de Zootecnia, Viçosa, v.27, n.5, p.988993, set./out. 1998. 